\title{
Histological analysis of loaded zirconia and titanium dental implants: an experimental study in the dog mandible
}

Thoma, Daniel S ; Benic, Goran I ; Muñoz, Fernando ; Kohal, Ralf ; Sanz Martin, Ignacio ; Cantalapiedra, Antonio González ; Hämmerle, Christoph H F ; Jung, Ronald E

\begin{abstract}
OBJECTIVE To assess whether or not peri-implant soft tissue dimensions and hard tissue integration of loaded zirconia implants are similar to those of a titanium implant. MATERIALS AND METHODS In six dogs, two one-piece zirconia implants (VC, ZD), a two-piece zirconia implant (BPI) and a control one-piece titanium implant (STM) were randomly placed. CAD/CAM crowns were cemented at 6 months. Six months later, animals were killed and histomorphometric analyses were performed, including: the level of the mucosal margin, the extent of the peri-implant mucosa, the marginal bone loss and the bone-to-implant contact (BIC). Means of outcomes variables were calculated together with their corresponding $95 \%$ confidence intervals. RESULTS In general, the mucosal margin was located coronally to the implant shoulder. The buccal peri-implant mucosa ranged between $2.64 \pm 0.70 \mathrm{~mm}(\mathrm{VC})$ and $3.03 \pm 1.71 \mathrm{~mm}(\mathrm{ZD})$ (for all median comparisons $\mathrm{p}>0.05$ ). The relative marginal bone loss ranged between $0.65 \pm 0.61 \mathrm{~mm}(\mathrm{BPI})$ and $1.73 \pm 1.68 \mathrm{~mm}$ (ZD) (buccal side), and between $0.55 \pm 0.37 \mathrm{~mm}$ $(\mathrm{VC})$ and $1.69 \pm 1.56 \mathrm{~mm}(\mathrm{ZD})$ (lingual side) $(\mathrm{p}>0.05)$. The mean BIC ranged between $78.6 \% \pm 17.3 \%(\mathrm{ZD})$ and $87.9 \% \pm 13.6 \%$ (STM) without statistically significant differences between the groups $(\mathrm{p}>0.05)$. CONCLUSIONS One- and two-piece zirconia rendered similar peri-implant soft tissue dimensions and osseointegration compared to titanium implants that were placed at 6 months of loading. Zirconia implants, however, exhibited a relatively high fracture rate.
\end{abstract}

DOI: https://doi.org/10.1111/jcpe.12453

Posted at the Zurich Open Repository and Archive, University of Zurich ZORA URL: https://doi.org/10.5167/uzh-115446

Journal Article

Accepted Version

Originally published at:

Thoma, Daniel S; Benic, Goran I; Muñoz, Fernando; Kohal, Ralf; Sanz Martin, Ignacio; Cantalapiedra, Antonio González; Hämmerle, Christoph H F; Jung, Ronald E (2015). Histological analysis of loaded zirconia and titanium dental implants: an experimental study in the dog mandible. Journal of Clinical Periodontology, 42(10):967-975. DOI: https://doi.org/10.1111/jcpe.12453 


\section{Histological analysis of loaded zirconia and titanium dental implants. An experimental study in the dog mandible.}

Daniel S. Thoma ${ }^{1}$, Goran I. Benic ${ }^{1}$, Fernando Munoz ${ }^{2}$, Ralf Kohal ${ }^{3}$, Ignacio Sanz Martin ${ }^{4}$, Antonio González Cantalapiedra², Christoph H. F. Hämmerle ${ }^{1}$, Ronald E. Jung ${ }^{1}$

Key words: dental implants, bone, histology, zirconium oxide, titanium, crowns (all Mesh terms)

Running title: tissue integration of zirconia implants

Number of figures: $x$

Number of tables: $\mathrm{x}$

Address for correspondence: $\quad$ PD Dr. Daniel S. Thoma

Clinic of Fixed and Removable Prosthodontics and

Dental Material Science

Center of Dental Medicine, University of Zurich

Plattenstrasse 11

$\mathrm{CH}-8032$ Zurich, Switzerland

Phone: +41446343260

Fax: +41446344305

e-mail: daniel.thoma@zzm.uzh.ch

${ }^{1}$ Clinic of Fixed and Removable Prosthodontics and Dental Material Science, University of Zurich, Zurich, Switzerland

${ }^{2}$ Department of Veterinary Clinical Sciences, University of Santiago de Compostela, Lugo, Spain

${ }^{3}$ Department of Prosthodontics, Albert-Ludwigs-University, Freiburg, Germany

${ }^{4}$ Universidad Complutense. Madrid, Spain 


\section{Clinical ReLeVANCE}

Scientific rationale for the study: Patient demands include alternatives to classic titanium dental implants. For that purpose, zirconia implants were developed and brought on the market. Even though the number of dental implants made of zirconia is increasing, preclinical and clinical data are scarce comparing titanium and zirconia one- and two-piece dental implants on a soft and hard tissue level or with or without a loading period.

Principal findings: After a loading period of 6 months one- and two-piece zirconia and one-piece titanium dental implants render similar peri-implant soft tissue dimensions in terms of the extent of the junctional epithelium and the peri-implant mucosa. The relative marginal bone loss depends on the individual implant design. Fractures of zirconia implants were frequent, however. Practical implications: Within the limitations of this study zirconia and titanium dental implants render similar hard and soft tissue integration. Zirconia implants should be compared to titanium dental implants in long-term randomized controlled clinical trials. 


\section{Abstract}

Objective: To assess whether or not peri-implant soft tissue dimensions and hard tissue integration of loaded zirconia implants are similar to those of a titanium implant.

Materials and methods: In 6 dogs, two one-piece zirconia implants (VC, ZD), a two-piece zirconia implant (BPI) and a control one-piece titanium implant (STM) were randomly placed. CAD/CAM crowns were cemented at 6 months. Six months later, animals were sacrificed and histomorphometric analyses performed, including: the level of the mucosal margin, the extent of the peri-implant mucosa, the marginal bone loss and the bone-to-implant contact (BIC). Means of outcomes variables were calculated together with their corresponding $95 \%$ confidence intervals.

Results: In general, the mucosal margin was located coronally to the implant shoulder. The buccal peri-implant mucosa ranged between $2.64 \mathrm{~mm} \pm 0.70 \mathrm{~mm}(\mathrm{VC})$ and $3.03 \mathrm{~mm} \pm 1.71 \mathrm{~mm}$ (ZD) (for all median comparisons $\mathrm{p}>0.05$ ). The relative marginal bone loss ranged between

$0.65 \mathrm{~mm} \pm 0.61 \mathrm{~mm} \quad$ (BPI) and $1.73 \mathrm{~mm} \pm 1.68 \mathrm{~mm}$ (ZD) (buccal side) and between $0.55 \mathrm{~mm} \pm 0.37 \mathrm{~mm}(\mathrm{VC})$ and $1.69 \mathrm{~mm} \pm 1.56 \mathrm{~mm}(Z D)$ (lingual side) ( $>>0.05)$. The mean BIC ranged between $78.6 \% \pm 17.3 \%$ (ZD) and $87.9 \% \pm 13.6 \%$ (STM) without statistically significant differences between the groups $(p>0.05)$.

Conclusions: One- and two-piece zirconia rendered similar peri-implant soft tissue dimensions and osseointegration compared to titanium implants 6 months of loading. Zirconia implants, however, exhibited a relatively high fracture rate. 


\section{Introduction}

Dental implants made of titanium and titanium alloys are considered as the gold standard and have successfully been used for a variety of indications including the support of removable prostheses, fixed single tooth reconstructions and fixed dental prostheses (Pjetursson et al., 2012, Jung et al., 2012, Roccuzzo et al., 2012). Hard and soft tissue integration as well as the clinical performance of titanium and titanium alloy implants were studied in numerous preclinical and clinical studies (Abrahamsson and Cardaropoli, 2007, Rasmusson et al., 2005, Albrektsson and Wennerberg, 2004b, Albrektsson and Wennerberg, 2004a, Attard and Zarb, 2004a, Attard and Zarb, 2004b, Buser et al., 2002, Buser et al., 1997).

Basically, two types of dental implants exist: i) one-piece dental implants and ii) two-piece dental implants. Both types of implants were studied extensively in preclinical experiments to document peri-implant soft tissue dimensions and hard tissue integration on a histologic level (Cochran et al., 1997, Hermann et al., 2000, Hermann et al., 2001, Abrahamsson et al., 1999). This included studies with focus on the differences between one- and two-piece dental implants, the influence of the healing protocol (submerged vs. transmucosal), the influence of the design of the implantabutment junction and different implant surfaces. The design of the implant-abutment junction (for two-piece dental implants) and the type of implant (one- or two-piece) are considered to have a major impact on the dimension of the peri-implant soft tissue and the marginal bone loss (Hermann et al., 2000, Broggini et al., 2006, King et al., 2002). The extent of the marginal bone loss relative to the implant shoulder appears to be typical for every implant type and design (Abrahamsson and Berglundh, 2009, Bateli et al., 2011, Al-Nsour et al., 2012). In addition, the timing for the marginal bone loss is also specific for every implant type: e.g. two-piece dental implants demonstrate the greatest extent of marginal bone loss after abutment connection (Ericsson et al., 1996, Roos et al., 1997).

More recently, new dental implant materials, most notably zirconia, were brought on the market. Similar to titanium implants, one- and two-piece zirconia dental implants exist (Depprich et al., 2008a, Depprich et al., 2008b, Depprich et al., 2008c, Gahlert et al., 2007, Kohal et al., 2004, Oliva et al., 2007, Payer et al., 2015, Cionca et al., 2015). Even though the number of dental 
implants made of zirconia is increasing, preclinical and clinical data are scarce comparing titanium and zirconia one- and two-piece dental implants on a soft and hard tissue level or with or without a loading period.

The aim of the present experiment was to histologically assess whether or not peri-implant soft tissue dimensions and hard tissue integration of loaded one- and two-piece zirconia implants are comparable to those of a grade 4 titanium one-piece dental implant. 


\section{Materials and methods}

\section{Study design}

This study was designed as a randomized controlled experimental study employing 6 female beagle dogs with a mean age of 30 months (weight 16.6 to $22.4 \mathrm{~kg}$ ). Upon approval of the protocol by the local ethical committee (AE-LU-001/11/PRODMED 03/3-11), the study was performed at the Facultad de Veterinaria, Campus Universitario $s / n$, Lugo, Spain, according to the guidelines of the Spanish law of animal keeping. The animals were kept in individual cages. The diet consisted of granulated food previously wetted in water and free access to tap water. All animals were enrolled in a plaque control program (cleaning of teeth and implants three times a week with brushes and chlorhexidine gel) during the entire study period.

\section{Surgical and prosthetic protocol}

The surgical and prosthetic protocol has already been described in detail elsewhere (Thoma et al., 2015). In brief, all premolars (P1, P2, P3, and P4) and the first molars (M1) were bilaterally extracted in the lower jaw. Four months later, four dental implants were placed according to a computer-generated randomization list on both sides of the mandible in all six dogs. The following four types of implants were included:

1. BPI, bpisys.ceramic, diameter $4.1 \mathrm{~mm}$, length $8 \mathrm{~mm}$, nanostructured, hydrophilic surface, BPI Biologisch Physikalische Implantate GmbH \& Co., Stuttgart, Germany (two-piece zirconia)

2. VC, vitaclinical ceramic.implant, diameter $4 \mathrm{~mm}$, length $8 \mathrm{~mm}$, VITA Zahnfabrik H. Rauter GmbH \& Co. KG, Bad Säckingen, Germany (one-piece zirconia)

3. ZD, Ziraldent, diameter $3.7 \mathrm{~mm}$, length $9 \mathrm{~mm}$, microporous surface, Metoxit AG, Thayngen, Switzerland) (one-piece zirconia)

4. STM, Straumann Standard Tissue Level implant, diameter $3.3 \mathrm{~mm}$, length $8 \mathrm{~mm}$, made of titanium grade 4 with a sandblasted, acid-etched (SLA) surface, Institut Straumann AG, Basel, Switzerland (one-piece titanium grade 4)

All implants were left for transmucosal healing. For that purpose, healing abutments were connected to the STM and BPI implants. The healing abutments were made of titanium (STM) 
and of polyether ether ketone (BPI). No further abutments or healing caps were connected to VC and ZD implants.

Six months after implant placement, standardized titanium abutments were connected to STM (Ref. 048.540; RN solid abutment 6०; Institut Straumann AG, Basel, Switzerland) and BPI implants (Ref. 74100, BPI Biologisch Physikalische Implantate GmbH \& Co., Stuttgart, Germany). No additional abutments were connected to VC and ZD implants. CAD/CAM fabricated crowns made of cobalt-chromium alloy were inserted using glass-ionomer cement (Ketac Cem, 3M Espe).

After a loading period of six months following crown insertion, the animals were painlessly sacrificed by an injection of lethal doses of sodium pentobarbital. The soft tissues surrounding the implants and crowns were macroscopically inspected for dehiscences or any other lesions. Subsequently, the 2 hemi-mandibles were block resected and fixed by immersion in $10 \%$ formaldehyde in phosphate buffer at $\mathrm{pH} 7$.

Histologic preparation

For the histologic samples $\mathrm{x}$-rays were taken of each site in order to accurately determine the cutting planes. The 48 sites ( 8 per animal) were dehydrated in a series of graded alcohol solutions and embedded in PMMA (polymethylmetacrylate, Merck AG, Darmstadt, Germany). From each specimen, one central orofacial section through the implant was prepared for histological assessment. Longitudinal sections through the implant of 60 to $70 \mu \mathrm{m}$ thickness were obtained by a microcutting and grinding technique adapted by Donath (Donath and Breuner, 1982). Thereafter, the sections were stained with van Gieson.

Analyses

Histometric analyses

Computer-assisted histometric measurements were performed using an automated image analysis system (Visiopharm Integrator System $®$, Visiopharm A/S, Hørsholm, Denmark), coupled with a video camera (Nikon Digital Sight DS-5Mc, Nikon, Egg, Switzerland) mounted on a light microscope (Nikon Eclipse 90i, Nikon, Egg, Switzerland). All reference points in the histologic sections were marked by two examiners independently and thereafter compared and 
discussed to aim for congruence. The linear measurements were then obtained by one examiner.

\section{Peri-implant soft tissue dimensions}

The following reference points were manually marked on the computer screen using a digital pen: margo mucosae (MM); implant shoulder (IS); apical extension of the junctional epithelium (aJE); first bone-to-implant contact (fBIC); bone crest (BC) (Figure 1).

This allowed the measurement of the following distances and dimensions:

- level of the margo mucosae (MM) relative to implant shoulder (IS) (MM to IS)

- length of the junctional epithelium (MM to aJE)

- peri-implant mucosa (MM to fBIC)

- marginal bone loss (BC to fBIC)

Bone to implant contact (BIC)

In addition, the BIC along the implant surfaces was calculated separately for buccal and lingual sides (Figure 2). For that purpose, a region of interest (ROI) was defined with a length of $4 \mathrm{~mm}$ in the center on the buccal and lingual side of each implant.

\section{Statistical analysis}

The effect of implant type on the primary endpoint "mean BIC" was assessed using a linear mixed model containing fixed effects for the implant type, side and position. The repeated measurements within the dogs ( 2 sides with 4 positions/implants each) are accounted for by a random effect (sides nested within dogs, with compound symmetric covariance structure). The pairwise tests on difference between the implant types with respect to the primary endpoint are adjusted for multiple testing using a Tukey-Kramer correction. P values $<0.05$ were considered to be significant. Least Squares Means and Differences of Least Squares Means were calculated together with their corresponding $95 \%$ confidence intervals and adjusted $95 \%$ confidence intervals, respectively. Secondary endpoints were analyzed analogously. All analyses have been conducted using SAS 9.2. 


\section{Results}

All dogs remained healthy during the entire study period and neither systemic nor local adverse events were observed. During the study period, a number of implants fractured: until crown insertion, two implants fractured (one VC, one ZD), during the 6 months loading period 4 more implants fractured (three ZD, one BPI), one implant partly fractured (one ZD), whereas one implant had lost osseointegration (one VC).

\section{Histometric analyses}

Descriptive data for the level of the margo mucosae relative to the implant shoulder, the length of the junctional epithelium, the peri-implant mucosa and the marginal bone loss are displayed in Tables 1 and 2. Figure 3 represent light micrographs at 25x magnification for all implant types.

\section{Peri-implant soft tissue dimensions}

The mean level of the margo mucosae was located apically relative to the implant shoulder for STM implants $(1.14 \mathrm{~mm} \pm 0.86 \mathrm{~mm})$ and $Z D$ implants $(1.39 \mathrm{~mm} \pm 0.56 \mathrm{~mm})$ on the buccal side and $0.49 \mathrm{~mm} \pm 0.86 \mathrm{~mm}$ for STM on the lingual side. For all other implant types and locations, the margo mucosae was located coronally relative to the implant shoulder on both the lingual and buccal side. The median differences between the groups were all statistically significant $(p<0.05)$, except for the comparison STM vs. ZD $(p>0.05)$ on the buccal side. On the lingual side, only the differences between BPI vs. STM and STM vs. VC were statistically significantly different $(p<0.05)$. 
The mean length of the junctional epithelium was very consistent for all four groups ranging between $1.41 \mathrm{~mm} \pm 0.85 \mathrm{~mm}(\mathrm{STM})$ and $1.44 \mathrm{~mm} \pm 0.60 \mathrm{~mm}(Z D)$ on the buccal side. The median differences between the groups were not statistically significantly different $(p>0.05)$. On the lingual side, however, the mean length of the junctional epithelium varied to a greater extent, with a minimal dimension for BPI $(1.41 \mathrm{~mm} \pm 0.86 \mathrm{~mm})$ and a maximal dimension for ZD $(3.57 \mathrm{~mm} \pm 1.40 \mathrm{~mm})$. The ZD group demonstrated a significantly larger dimension of the junctional epithelium compared to all other groups $(p<0.05)$.

Similar to the length of the junctional epithelium, the peri-implant mucosa was very constant on the buccal side for all groups ranging between $2.64 \mathrm{~mm} \pm 0.70 \mathrm{~mm}(\mathrm{VC})$ and $3.03 \mathrm{~mm} \pm 1.71 \mathrm{~mm}$ (ZD) (for all median comparisons $\mathrm{p}>0.05$ ). On the lingual side, the dimension increased again (minimum for BPI: $3.07 \mathrm{~mm} \pm 1.11 \mathrm{~mm}$; maximum for ZD: $5.05 \mathrm{~mm} \pm 2.07 \mathrm{~mm}$ ). Significant differences were observed between ZD and all other groups $(p<0.05)$.

The relative marginal bone loss measured as the distance between the implant shoulder and the bone crest ranged between $0.65 \mathrm{~mm} \pm 0.61 \mathrm{~mm}(B P I)$ and $1.73 \mathrm{~mm} \pm 1.68 \mathrm{~mm}(Z \mathrm{D})$ on the buccal side and between $0.55 \mathrm{~mm} \pm 0.37 \mathrm{~mm}(\mathrm{VC})$ and $1.69 \mathrm{~mm} \pm 1.56 \mathrm{~mm}(\mathrm{ZD})$ on the lingual side. None of the differences were statistically significantly different between the groups $(p>0.05)$.

Bone-to-implant contact (BIC)

Table 3 displays all data for the BIC. The mean BIC (buccal and lingual) was lowest for ZD implants with $78.6 \%( \pm 17.3 \%)$ and highest for the control implants (STM) with $87.9 \%$ ( \pm 13.6\%). The median differences between the four groups were not statistically significant $(p>0.05)$. 


\section{Discussion}

The results of the present preclinical study demonstrated that, in general, after a loading period of 6 month: i) one- and two-piece zirconia and one-piece titanium dental implants render similar peri-implant soft tissue dimensions in terms of the extent of the junctional epithelium and the peri-implant mucosa; ii) the level of the margo mucosae relative to the implant shoulder depends on the individual implant design; iii) the extent of the relative marginal bone loss depends also on the individual implant design; and, iv) the bone to implant contact was similar for zirconia and titanium implants.

Around teeth, the periodontium is developed during tooth eruption and serves as a sealer against the oral cavity. The peri-implant mucosa forms after implant placement or abutment connection and the adaptation with a mucoperiosteal flap around the implant neck. During the wound healing process, the peri-implant tissues are established. The differences between the natural gingiva around teeth and the peri-implant mucosa were studied in an early preclinical study in dog (Berglundh et al., 1991, Berglundh et al., 2007). It was demonstrated that the periimplant mucosa consists of a well-keratinized mucosa at the outer surface, and is connected to a long junctional epithelium at the inner surface. This junctional epithelium is facing the abutment and the supracrestal part of the implant. At the apical end of the junctional epithelium, a connective tissue is located on top of the bone crest. The overall dimension of the peri-implant mucosa was calculated to be $3.80 \mathrm{~mm}$ (compared to $3.17 \mathrm{~mm}$ around teeth). In comparison to teeth, the dimension of the connective tissue was significantly greater (Berglundh et al., 1991). Further studies demonstrated that the dimension of the peri-implant tissues appear to be constant and independent of the implant system and the healing mode (Cochran et al., 2013, Bakaeen et al., 2009, Deporter et al., 2008, Abrahamsson et al., 1999, Abrahamsson et al., 1996, Parpaiola et al., 2015). This observation was confirmed in the present study with periimplant soft tissue dimension very similar for one-piece titanium implants and one- and twopiece zirconia implants. On the buccal side, the dimension of the peri-implant mucosa was constant for all four groups with a range between $2.64 \mathrm{~mm}$ and $3.03 \mathrm{~mm}$. On the lingual side, 
however, the dimension of the peri-implant mucosa was in general slightly greater with mean values ranging between $3.07 \mathrm{~mm}$ and $3.40 \mathrm{~mm}$. One one-piece zirconia implant (ZD) demonstrated a significantly greater dimension of $5.05 \mathrm{~mm}$ on the lingual side. The reason for this increase in height may be explained by the fact that also more marginal bone was lost between implant placement and 6 months of loading for this specific type of implant. Apart from the above-mentioned studies, a couple of investigations analyzed the peri-implant soft tissue dimensions also clinically and further confirm the outcomes of the present study. The obtained dimensions for the peri-implant mucosa ranged between $2.55 \mathrm{~mm}$ and $3.6 \mathrm{~mm}$ (Tomasi et al., 2014, Judgar et al., 2014).

The level of the margo mucosae relative to the implant shoulder is a critical issue in daily practice mainly for esthetic purposes. From a biological point of view, dental implants designed as one-piece types have a predefined part, mostly machined titanium that emerges through the peri-implant soft tissues. Ideally, the dimension of the transmucosal part matches the thickness of the individual's soft tissues. The one-piece dental implants used in the present study had varying transmucosal heights of $2.8 \mathrm{~mm}$ (STM), $2 \mathrm{~mm}$ (VC) and $2.6 \mathrm{~mm}$ (ZD). This was reflected in the level of the margo mucosae relative to the implant shoulder, with STM and ZD having the margo mucosae located more apically than the implant shoulder on the buccal side, whereas the VC implants with the shortest transmucosal height and the two-piece zirconia implants (BPI) having the margo mucosae located more coronally than the implant shoulder. On the lingual side, however, the peri-implant mucosa was greater for ZD, resulting in a submerged location of the implant shoulder. These differences with respect to the height of the transmucosal part of one-piece zirconia implants must be considered in clinical cases in order to optimized the esthetic outcome.

Based on the outcomes of a previous preclinical study, the dimension of the peri-implant mucosa is constant for a specific implant system (Berglundh and Lindhe, 1996). In case the dimension of the soft tissues is excised and/or less than $2 \mathrm{~mm}$, marginal bone loss occurs followed by the reestablishment of the peri-implant mucosa (Berglundh and Lindhe, 1996). This observation was further confirmed in a clinical study (Linkevicius et al., 2014). In that study, implants were 
placed at the bone crest in cases with thin and thick soft tissues. Significantly more marginal bone loss was observed for platform-switched implants with thin mucosal soft tissues (Linkevicius et al., 2014). In the present study, dental implants were placed according to the manufacturer's recommendations. Due to the nature of a clinical environment, STM and BPI implants were placed slightly below the ideal level, whereas VC and ZD implants were placed slightly above the ideal level (Thoma et al. 2014 accepted). This finally resulted in varying marginal bone loss as demonstrated in the histologic sections. More marginal bone loss was observed for STM and BPI compared to VC implants and confirmed the previously mentioned concept (Linkevicius et al., 2014, Berglundh and Lindhe, 1996). ZD implants however, revealed an even greater amount of marginal bone loss. The reason for this observation remains speculation, but must be attributed to this specific implant design. Variations in marginal bone loss might also be due to the observed misfit between the cemented crowns on top of the different implants. The histologic sections revealed in many cases a marginal gap. This gap might have contributed to more plaque accumulation, eventually leading to inflammation and changes of the peri-implant tissue dimensions. None of the implants, however, did demonstrate a superior fit of the crowns resulting in a more or less similar peri-implant tissue health between the different implant systems.

In a systematic review based on preclinical studies, the BIC values of zirconia and titanium dental implants were compared (Manzano et al., 2014). From a PubMed search, 19 preclinical studies fulfilled the inclusion criteria, were finally included in this review and BIC values analyzed. The review concluded that BIC values of zirconia implants in most of the studies did not show statistically significant differences compared with titanium implants. In addition, surface-modified zirconia implants may have the potential as a candidate for a successful implant material (Manzano et al., 2014). BIC values in the present study, obtained 12 months after implant placement and 6 months after the start of the loading period, ranged between $79 \%$ and $88 \%$ for zirconia and were $88 \%$ for STM (titanium implants with a sandblasted acid etched surface). This is in line with preclinical studies with a long-term follow-up of at least 3 months and reported BIC values ranging between $41 \%$ and $84 \%$ for titanium implants in larger species 
(mini-pigs, pigs, canines, monkeys) (Kohal et al., 2004, Depprich et al., 2008c, Gahlert et al., 2009, Stadlinger et al., 2010, Schliephake et al., 2010, Koch et al., 2010, Moller et al., 2012, Gahlert et al., 2012). The same studies reported BIC values for zirconia dental implants placed in various locations intra- and extraorally ranging between $48 \%$ and $71 \%$ (Kohal et al., 2004, Depprich et al., 2008c, Gahlert et al., 2009, Stadlinger et al., 2010, Schliephake et al., 2010, Koch et al., 2010, Moller et al., 2012, Gahlert et al., 2012).

From a clinical point of view, one-piece implants are more prone to occlusal load since they emerge through the mucosa during the healing phase between insertion and loading. Even though care was taken to reduce interocclusal contacts, the dogs continued to chew, resulting a relatively high number of fractures (all zirconia implants). However, one dog accounted for 4 out of 7 fractures obviously adding this dog as a confounding factor. In addition, most implants demonstrated some kind of wear on top at the day of the insertion of the crowns. This underlines that dogs, even though being fed with a soft diet, might apply relatively high occlusal forces. In the present study, the dimensions of the zirconia implants, mostly ZD implants, were not able to withstand these forces, which in turns implies that for this specific dog model, a higher fracture resistance is needed. These results are difficult to translate into daily practice and no critical implant dimension can be determined. 


\section{Conclusions}

One- and two-piece zirconia implants rendered similar peri-implant soft tissue dimensions in terms of the extent of the junctional epithelium and the peri-implant mucosa compared to titanium dental implants. The level of the margo mucosae relative to the implant's shoulder was associated with the sink depth at implant placement and the height of the transmucosal part of the implants. The implant design, the sink depth and the height of the transmucosal implant part of the implants influenced the extent of the relative marginal bone loss. The bone to implant contact was high and similar for zirconia and titanium implants after 12 months of osseointegration and a 6 months loading period. 


\section{Acknowledgements and conflict of interest}

The authors are grateful to Mrs. Gisela Müller, study monitor at the Clinic for Fixed and Removable Prosthodontics and Dental Material Science, University of Zurich for her support in the preparation of the manuscript. The help and support of the animal care team at the Facultad de Veterinaria, Campus Universitario s/n, Lugo, Spain is greatly acknowledged. The authors would also like to address gratitude to Ms. Sonja Hitz, Clinic of Fixed and Removable Prosthodontics and Dental Material Science, University of Zurich for the preparation of the histologic slides. The study was supported by a research grant of the Clinic for Fixed and Removable Prosthodontics and Dental Material Science, University of Zurich, Switzerland and VITA Zahnfabrik H. Rauter GmbH \& Co. KG, Bad Säckingen, Germany. In addition, dental implant materials were provided free of charge by BPI Biologisch Physikalische Implantate GmbH \& Co., Stuttgart, Germany, by Metoxit AG, Thayngen, Switzerland and by Institut Straumann AG, Basel, Switzerland. The authors do not report to have any conflict of interest to any products related to this study. 


\section{References}

Abrahamsson, I. \& Berglundh, T. (2009) Effects of different implant surfaces and designs on marginal bone-level alterations: a review. Clinical Oral Implants Research 20 Suppl 4, 207-215.

Abrahamsson, I., Berglundh, T., Moon, I. S. \& Lindhe, J. (1999) Peri-implant tissues at submerged and non-submerged titanium implants. Journal of Clinical Periodontology 26, 600-607.

Abrahamsson, I., Berglundh, T., Wennstrom, J. \& Lindhe, J. (1996) The peri-implant hard and soft tissues at different implant systems. A comparative study in the dog. Clinical Oral Implants Research 7, 212-219.

Abrahamsson, I. \& Cardaropoli, G. (2007) Peri-implant hard and soft tissue integration to dental implants made of titanium and gold. Clinical Oral Implants Research 18, 269-274.

Al-Nsour, M. M., Chan, H. L. \& Wang, H. L. (2012) Effect of the platform-switching technique on preservation of peri-implant marginal bone: a systematic review. International Journal of Oral and Maxillofacial Implants 27, 138-145.

Albrektsson, T. \& Wennerberg, A. (2004a) Oral implant surfaces: Part 1--review focusing on topographic and chemical properties of different surfaces and in vivo responses to them. International Journal of Prosthodontics 17, 536-543.

Albrektsson, T. \& Wennerberg, A. (2004b) Oral implant surfaces: Part 2--review focusing on clinical knowledge of different surfaces. International Journal of Prosthodontics 17, 544564.

Attard, N. J. \& Zarb, G. A. (2004a) Long-term treatment outcomes in edentulous patients with implant overdentures: the Toronto study. International Journal of Prosthodontics 17, 425 433.

Attard, N. J. \& Zarb, G. A. (2004b) Long-term treatment outcomes in edentulous patients with implant-fixed prostheses: the Toronto study. International Journal of Prosthodontics 17, 417-424. 
Bakaeen, L., Quinlan, P., Schoolfield, J., Lang, N. P. \& Cochran, D. L. (2009) The biologic width around titanium implants: histometric analysis of the implantogingival junction around immediately and early loaded implants. International Journal of Periodontics and Restorative Dentistry 29, 297-305.

Bateli, M., Att, W. \& Strub, J. R. (2011) Implant neck configurations for preservation of marginal bone level: a systematic review. International Journal of Oral and Maxillofacial Implants 26, 290-303.

Berglundh, T., Abrahamsson, I., Welander, M., Lang, N. P. \& Lindhe, J. (2007) Morphogenesis of the peri-implant mucosa: an experimental study in dogs. Clinical Oral Implants Research 18, 1-8.

Berglundh, T. \& Lindhe, J. (1996) Dimension of the periimplant mucosa. Biological width revisited. Journal of Clinical Periodontology 23, 971-973.

Berglundh, T., Lindhe, J., Ericsson, I., Marinello, C. P., Liljenberg, B. \& Thomsen, P. (1991) The soft tissue barrier at implants and teeth. Clinical Oral Implants Research 2, 81-90.

Broggini, N., McManus, L. M., Hermann, J. S., Medina, R., Schenk, R. K., Buser, D. \& Cochran, D. L. (2006) Peri-implant inflammation defined by the implant-abutment interface. Journal of Dental Research 85, 473-478.

Buser, D., Ingimarsson, S., Dula, K., Lussi, A., Hirt, H. P. \& Belser, U. C. (2002) Long-term stability of osseointegrated implants in augmented bone: a 5-year prospective study in partially edentulous patients. International Journal of Periodontics and Restorative Dentistry 22, 109-117.

Buser, D., Mericske-Stern, R., Bernard, J. P., Behneke, A., Behneke, N., Hirt, H. P., Belser, U. C. \& Lang, N. P. (1997) Long-term evaluation of non-submerged ITI implants. Part 1: 8-year life table analysis of a prospective multi-center study with 2359 implants. Clinical Oral Implants Research 8, 161-172.

Cionca, N., Muller, N. \& Mombelli, A. (2015) Two-piece zirconia implants supporting all-ceramic crowns: a prospective clinical study. Clinical Oral Implants Research 26, 413-418.

Cochran, D. L., Hermann, J. S., Schenk, R. K., Higginbottom, F. L. \& Buser, D. (1997) Biologic width around titanium implants. A histometric analysis of the implanto-gingival junction 
around unloaded and loaded nonsubmerged implants in the canine mandible. Journal of Periodontology 68, 186-198.

Cochran, D. L., Mau, L. P., Higginbottom, F. L., Wilson, T. G., Bosshardt, D. D., Schoolfield, J. \& Jones, A. A. (2013) Soft and hard tissue histologic dimensions around dental implants in the canine restored with smaller-diameter abutments: a paradigm shift in peri-implant biology. International Journal of Oral and Maxillofacial Implants 28, 494-502.

Deporter, D., Al-Sayyed, A., Pilliar, R. M. \& Valiquette, N. (2008) "Biologic width"and crestal bone remodeling with sintered porous-surfaced dental implants: a study in dogs. International Journal of Oral and Maxillofacial Implants 23, 544-550.

Depprich, R., Ommerborn, M., Zipprich, H., Naujoks, C., Handschel, J., Wiesmann, H. P., Kubler, N. R. \& Meyer, U. (2008a) Behavior of osteoblastic cells cultured on titanium and structured zirconia surfaces. Head Face Med 4, 29.

Depprich, R., Zipprich, H., Ommerborn, M., Mahn, E., Lammers, L., Handschel, J., Naujoks, C., Wiesmann, H. P., Kubler, N. R. \& Meyer, U. (2008b) Osseointegration of zirconia implants: an SEM observation of the bone-implant interface. Head Face Med 4, 25.

Depprich, R., Zipprich, H., Ommerborn, M., Naujoks, C., Wiesmann, H. P., Kiattavorncharoen, S., Lauer, H. C., Meyer, U., Kubler, N. R. \& Handschel, J. (2008c) Osseointegration of zirconia implants compared with titanium: an in vivo study. Head Face Med 4, 30.

Donath, K. \& Breuner, G. (1982) A method for the study of undecalcified bones and teeth with attached soft tissues. The Sage-Schliff (sawing and grinding) technique. Journal of Oral Pathology 11, 318-326.

Ericsson, I., Nilner, K., Klinge, B. \& Glantz, P. O. (1996) Radiographical and histological characteristics of submerged and nonsubmerged titanium implants. An experimental study in the Labrador dog. Clinical Oral Implants Research 7, 20-26.

Exner, H. E. (1987) A model stereological nomenclature. Acta Stereologica 6, 179-184.

Gahlert, M., Gudehus, T., Eichhorn, S., Steinhauser, E., Kniha, H. \& Erhardt, W. (2007) Biomechanical and histomorphometric comparison between zirconia implants with varying surface textures and a titanium implant in the maxilla of miniature pigs. Clinical Oral Implants Research 18, 662-668. 
Gahlert, M., Roehling, S., Sprecher, C. M., Kniha, H., Milz, S. \& Bormann, K. (2012) In vivo performance of zirconia and titanium implants: a histomorphometric study in mini pig maxillae. Clinical Oral Implants Research 23, 281-286.

Gahlert, M., Rohling, S., Wieland, M., Sprecher, C. M., Kniha, H. \& Milz, S. (2009) Osseointegration of zirconia and titanium dental implants: a histological and histomorphometrical study in the maxilla of pigs. Clinical Oral Implants Research 20, 1247-1253.

Hermann, J. S., Buser, D., Schenk, R. K. \& Cochran, D. L. (2000) Crestal bone changes around titanium implants. A histometric evaluation of unloaded non-submerged and submerged implants in the canine mandible. Journal of Periodontology 71, 1412-1424.

Hermann, J. S., Buser, D., Schenk, R. K., Schoolfield, J. D. \& Cochran, D. L. (2001) Biologic Width around one- and two-piece titanium implants. Clinical Oral Implants Research 12, 559-571.

Judgar, R., Giro, G., Zenobio, E., Coelho, P. G., Feres, M., Rodrigues, J. A., Mangano, C., Iezzi, G., Piattelli, A. \& Shibli, J. A. (2014) Biological Width around One- and Two-Piece Implants Retrieved from Human Jaws. Biomed Res Int 2014, 850120.

Jung, R. E., Zembic, A., Pjetursson, B. E., Zwahlen, M. \& Thoma, D. S. (2012) Systematic review of the survival rate and the incidence of biological, technical, and aesthetic complications of single crowns on implants reported in longitudinal studies with a mean follow-up of 5 years. Clinical Oral Implants Research 23 Suppl 6, 2-21.

King, G. N., Hermann, J. S., Schoolfield, J. D., Buser, D. \& Cochran, D. L. (2002) Influence of the size of the microgap on crestal bone levels in non-submerged dental implants: a radiographic study in the canine mandible. Journal of Periodontology 73, 1111-1117.

Koch, F. P., Weng, D., Kramer, S., Biesterfeld, S., Jahn-Eimermacher, A. \& Wagner, W. (2010) Osseointegration of one-piece zirconia implants compared with a titanium implant of identical design: a histomorphometric study in the dog. Clinical Oral Implants Research 21, 350-356. 
Kohal, R. J., Weng, D., Bachle, M. \& Strub, J. R. (2004) Loaded custom-made zirconia and titanium implants show similar osseointegration: an animal experiment. Journal of Periodontology 75, 1262-1268.

Linkevicius, T., Puisys, A., Steigmann, M., Vindasiute, E. \& Linkeviciene, L. (2014) Influence of Vertical Soft Tissue Thickness on Crestal Bone Changes Around Implants with Platform Switching: A Comparative Clinical Study. Clinical Implant Dentistry and Related Research.

Manzano, G., Herrero, L. R. \& Montero, J. (2014) Comparison of clinical performance of zirconia implants and titanium implants in animal models: a systematic review. International Journal of Oral and Maxillofacial Implants 29, 311-320.

Moller, B., Terheyden, H., Acil, Y., Purcz, N. M., Hertrampf, K., Tabakov, A., Behrens, E. \& Wiltfang, J. (2012) A comparison of biocompatibility and osseointegration of ceramic and titanium implants: an in vivo and in vitro study. International Journal of Oral and Maxillofacial Surgery 41, 638-645.

Oliva, J., Oliva, X. \& Oliva, J. D. (2007) One-year follow-up of first consecutive 100 zirconia dental implants in humans: a comparison of 2 different rough surfaces. International Journal of Oral and Maxillofacial Implants 22, 430-435.

Parpaiola, A., Cecchinato, D., Toia, M., Bressan, E., Speroni, S. \& Lindhe, J. (2015) Dimensions of the healthy gingiva and peri-implant mucosa. Clinical Oral Implants Research 26, 657662.

Payer, M., Heschl, A., Koller, M., Arnetzl, G., Lorenzoni, M. \& Jakse, N. (2015) All-ceramic restoration of zirconia two-piece implants--a randomized controlled clinical trial. Clinical Oral Implants Research 26, 371-376.

Pjetursson, B. E., Thoma, D., Jung, R., Zwahlen, M. \& Zembic, A. (2012) A systematic review of the survival and complication rates of implant-supported fixed dental prostheses (FDPs) after a mean observation period of at least 5 years. Clinical Oral Implants Research $\mathbf{2 3}$ Suppl 6, 22-38.

Rasmusson, L., Roos, J. \& Bystedt, H. (2005) A 10-year follow-up study of titanium dioxideblasted implants. Clinical Implant Dentistry and Related Research 7, 36-42. 
Roccuzzo, M., Bonino, F., Gaudioso, L., Zwahlen, M. \& Meijer, H. J. (2012) What is the optimal number of implants for removable reconstructions? A systematic review on implantsupported overdentures. Clinical Oral Implants Research 23 Suppl 6, 229-237.

Roos, J., Sennerby, L., Lekholm, U., Jemt, T., Grondahl, K. \& Albrektsson, T. (1997) A qualitative and quantitative method for evaluating implant success: a 5-year retrospective analysis of the Branemark implant. International Journal of Oral and Maxillofacial Implants 12, 504514.

Schliephake, H., Hefti, T., Schlottig, F., Gedet, P. \& Staedt, H. (2010) Mechanical anchorage and peri-implant bone formation of surface-modified zirconia in minipigs. Journal of Clinical Periodontology 37, 818-828.

Stadlinger, B., Hennig, M., Eckelt, U., Kuhlisch, E. \& Mai, R. (2010) Comparison of zirconia and titanium implants after a short healing period. A pilot study in minipigs. International Journal of Oral and Maxillofacial Surgery 39, 585-592.

Thoma, D. S., Benic, G. I., Munoz, F., Kohal, R. J., Sanz Martin, I., Cantalapiedra, A. G., Hammerle, C. H. F. \& Jung, R. E. (2015) Marginal bone level alterations of loaded zirconia and titanium dental implants. An experimental study in the dog mandible. Clinical Oral Implants Research.

Tomasi, C., Tessarolo, F., Caola, I., Wennstrom, J., Nollo, G. \& Berglundh, T. (2014) Morphogenesis of peri-implant mucosa revisited: an experimental study in humans. Clinical Oral Implants Research 25, 997-1003. 


\section{Figure legends}

Figure 1. Histomorphometric assessment. Included references: aJE=apical extension of junctional epithelium. $\mathrm{BC}=$ bone crest. $\mathrm{fBIC}=$ first bone to implant contact. $\mathrm{IS}=$ implant shoulder. $\mathrm{MM}=$ margo mucosae.

Figure 2. Histomorphometric assessment of bone to implant contact (BIC) performed on the buccal and lingual side standardized in the center of the implants along a distance of $4 \mathrm{~mm}$. Pink line $=$ soft tissue in contact with implant surface. Yellow line=bone in contact with implant surface.

Figure 3. Light micrographs at 25x magnification. A. STM=one-piece titanium implant. B. BPI=two-piece zirconia implant. C. VC= one-piece zirconia implant. D. ZD= one-piece zirconia implant.

Table 1. Descriptive analysis for MM to IS = level of the margo mucosae relative to implant shoulder, MM to aJE = length of the junctional epithlium, MM to fBIC = length of the peri-implant mucosa , and $B C$ to $\mathrm{fBIC}=$ marginal bone loss including standard deviation (SD) and $95 \%$ confidence interval on the buccal side. STM=one-piece titanium implant; BPI=two-piece zirconia implant; VC and ZD = one-piece zirconia implants; aJE=apical extension of junctional epithelium. $\mathrm{BC}=$ bone crest. $\mathrm{fBIC}=$ first bone to implant contact. $\mathrm{IS}=$ implant shoulder. $\mathrm{MM}=$ margo mucosae.

Table 2. Descriptive analysis for MM to IS = level of the margo mucosae relative to implant shoulder, $\mathrm{MM}$ to $\mathrm{aJE}=$ length of the junctional epithlium, MM to $\mathrm{fBIC}=$ length of the peri-implant mucosa, and BC to $\mathrm{fBIC}=$ marginal bone loss including standard deviation (SD) and $95 \%$ confidence interval on the lingual side. STM=one-piece titanium implant; BPI=two-piece zirconia implant; VC and ZD = one-piece zirconia implants; aJE=apical extension of junctional epithelium. $\mathrm{BC}=$ bone crest. $\mathrm{fBIC}=$ first bone to implant contact. $\mathrm{IS}=$ implant shoulder. $\mathrm{MM}=$ margo mucosae.

Table 3. Descriptive analysis for mean bone to implant contact including standard deviation (SD) and $95 \%$ confidence interval. STM=one-piece titanium implant; BPI=two-piece zirconia implant; VC and ZD = one-piece zirconia implants. 


\section{Table 1:}

\begin{tabular}{|c|c|c|c|c|}
\hline Time-point & STM & BPI & VC & ZD \\
\hline & $\begin{array}{c}\mathrm{n} \text { dogs } \\
\mathrm{n} \text { sections } \\
\text { Mean } \pm \mathrm{SD} \\
\text { Median }(\mathrm{Q} 1, \mathrm{Q} 3)\end{array}$ & $\begin{array}{c}\mathrm{n} \text { dogs } \\
\mathrm{n} \text { sections } \\
\text { Mean } \pm \mathrm{SD} \\
\text { Median }(\mathrm{Q} 1, \mathrm{Q} 3)\end{array}$ & $\begin{array}{c}\mathrm{n} \text { dogs } \\
\mathrm{n} \text { sections } \\
\text { Mean } \pm \mathrm{SD} \\
\text { Median }(\mathrm{Q} 1, \mathrm{Q} 3)\end{array}$ & $\begin{array}{c}\mathrm{n} \text { dogs } \\
\mathrm{n} \text { sections } \\
\text { Mean } \pm \mathrm{SD} \\
\text { Median }(\mathrm{Q} 1, \mathrm{Q} 3)\end{array}$ \\
\hline MM to IS buccal & $\begin{array}{c}6 \\
12 \\
1.14 \pm 0.86 \\
1.20(0.85,1.66)\end{array}$ & $\begin{array}{c}6 \\
11 \\
-1.34 \pm 0.62 \\
-1.46(-1.64,-0.94)\end{array}$ & $\begin{array}{c}6 \\
11 \\
-0.52 \pm 1.03 \\
-0.44(-1.35,0.26)\end{array}$ & $\begin{array}{c}6 \\
6 \\
1.39 \pm 0.56 \\
1.42(0.90,1.83)\end{array}$ \\
\hline MM to aJE buccal & $\begin{array}{c}6 \\
12 \\
1.41 \pm 0.85 \\
1.21(1.78,0.93)\end{array}$ & $\begin{array}{c}6 \\
11 \\
1.41 \pm 0.57 \\
1.27(2.16,0.91)\end{array}$ & $\begin{array}{c}6 \\
11 \\
1.44 \pm 0.84 \\
1.38(1.57,0.77)\end{array}$ & $\begin{array}{c}6 \\
6 \\
1.44 \pm 0.60 \\
1.53(1.85,1.13)\end{array}$ \\
\hline MM to fBIC buccal & $\begin{array}{c}6 \\
12 \\
2.78 \pm 0.82 \\
2.68(3.32,2.10)\end{array}$ & $\begin{array}{c}6 \\
11 \\
2.71 \pm 1.00 \\
2.58(3.33,2.38)\end{array}$ & $\begin{array}{c}6 \\
10 \\
2.64 \pm 0.70 \\
2.55(3.00,2.33)\end{array}$ & $\begin{array}{c}6 \\
6 \\
3.03 \pm 1.71 \\
2.41(2.84,2.16)\end{array}$ \\
\hline$B C$ to $f B I C$ buccal & $\begin{array}{c}6 \\
12 \\
-0.79 \pm 0.63 \\
-0.60(-1.25,-0.31)\end{array}$ & $\begin{array}{c}6 \\
11 \\
-0.65 \pm 0.61 \\
-0.51(-1.00,-0.13)\end{array}$ & $\begin{array}{c}6 \\
10 \\
-0.69 \pm 0.50 \\
-0.69(-1.01,-0.40)\end{array}$ & $\begin{array}{c}6 \\
6 \\
-1.73 \pm 1.68 \\
-1.15(-1.85,-0.68)\end{array}$ \\
\hline
\end{tabular}


Table 2:

\begin{tabular}{|c|c|c|c|c|}
\hline Time-point & STM & BPI & VC & ZD \\
\hline & $\begin{array}{c}\mathrm{n} \text { dogs } \\
\mathrm{n} \text { sections } \\
\text { Mean } \pm \mathrm{SD} \\
\text { Median }(\mathrm{Q} 1, \mathrm{Q} 3)\end{array}$ & $\begin{array}{c}\mathrm{n} \text { dogs } \\
\mathrm{n} \text { sections } \\
\text { Mean } \pm \mathrm{SD} \\
\text { Median }(\mathrm{Q} 1, \mathrm{Q} 3)\end{array}$ & $\begin{array}{c}n \text { dogs } \\
n \text { sections } \\
\text { Mean } \pm S D \\
\text { Median }(\mathrm{Q} 1, \mathrm{Q} 3)\end{array}$ & $\begin{array}{c}\mathrm{n} \text { dogs } \\
\mathrm{n} \text { sections } \\
\text { Mean } \pm \mathrm{SD} \\
\text { Median }(\mathrm{Q} 1, \mathrm{Q} 3)\end{array}$ \\
\hline MM to IS lingual & $\begin{array}{c}6 \\
12 \\
0.49 \pm 0.86 \\
0.72(-0.22,1.24) \\
\end{array}$ & $\begin{array}{c}6 \\
11 \\
-1.51 \pm 0.88 \\
-1.25(-2.35,-0.70)\end{array}$ & $\begin{array}{c}6 \\
11 \\
-0.92 \pm 0.96 \\
-0.58(-1.96,-0.18)\end{array}$ & $\begin{array}{c}6 \\
6 \\
-0.76 \pm 1.13 \\
-0.76(-1.91,0.38)\end{array}$ \\
\hline MM to aJE lingual & $\begin{array}{c}6 \\
12 \\
2.03 \pm 0.78 \\
2.09(2.50,1.51)\end{array}$ & $\begin{array}{c}6 \\
11 \\
1.41 \pm 0.86 \\
1.54(1.86,0.51)\end{array}$ & $\begin{array}{c}6 \\
11 \\
1.65 \pm 0.94 \\
1.99(2.19,0.61)\end{array}$ & $\begin{array}{c}6 \\
6 \\
3.57 \pm 1.40 \\
3.72(4.76,2.46)\end{array}$ \\
\hline MM to fBIC lingual & $\begin{array}{c}6 \\
12 \\
3.40 \pm 0.85 \\
3.22(3.94,2.72)\end{array}$ & $\begin{array}{c}6 \\
11 \\
3.07 \pm 1.11 \\
2.95(3.19,2.53)\end{array}$ & $\begin{array}{c}6 \\
10 \\
3.26 \pm 0.62 \\
3.07(3.39,2.96)\end{array}$ & $\begin{array}{c}6 \\
6 \\
5.05 \pm 2.07 \\
4.30(5.36,3.80)\end{array}$ \\
\hline$B C$ to $f B I C$ lingual & $\begin{array}{c}6 \\
12 \\
-0.75 \pm 0.58 \\
-0.54(-1.24,-0.24)\end{array}$ & $\begin{array}{c}6 \\
11 \\
-0.91 \pm 1.13 \\
-0.54(-1.25,-0.09)\end{array}$ & $\begin{array}{c}6 \\
10 \\
-0.55 \pm 0.37 \\
-0.49(-0.87,-0.30)\end{array}$ & $\begin{array}{c}6 \\
6 \\
-1.69 \pm 1.56 \\
-1.03(-1.24,-1.01)\end{array}$ \\
\hline
\end{tabular}


Table 3:

\begin{tabular}{|c|c|c|c|c|}
\hline Time-point & STM & BPI & VC & ZD \\
\hline & $\begin{array}{c}\mathrm{n} \text { dogs } \\
\mathrm{n} \text { sections } \\
\text { Mean } \pm \mathrm{SD} \\
\text { Median }(\mathrm{Q} 1, \mathrm{Q} 3) \\
\end{array}$ & $\begin{array}{c}\mathrm{n} \text { dogs } \\
\mathrm{n} \text { sections } \\
\text { Mean } \pm \mathrm{SD} \\
\text { Median }(\mathrm{Q} 1, \mathrm{Q} 3) \\
\end{array}$ & $\begin{array}{c}\mathrm{n} \text { dogs } \\
\mathrm{n} \text { sections } \\
\text { Mean } \pm \mathrm{SD} \\
\text { Median }(\mathrm{Q} 1, \mathrm{Q} 3) \\
\end{array}$ & $\begin{array}{c}\mathrm{n} \text { dogs } \\
\mathrm{n} \text { sections } \\
\text { Mean } \pm \mathrm{SD} \\
\text { Median }(\mathrm{Q} 1, \mathrm{Q} 3) \\
\end{array}$ \\
\hline $\begin{array}{l}\text { bone to implant } \\
\text { contact }\end{array}$ & $\begin{array}{c}6 \\
12 \\
87.85 \pm 13.59 \\
92.76(80.24,99.22)\end{array}$ & $\begin{array}{c}6 \\
12 \\
84.17 \pm 25.07 \\
95.50(80.77,98.48)\end{array}$ & $\begin{array}{c}6 \\
11 \\
87.71 \pm 25.07 \\
97.50(91.02,100.00)\end{array}$ & $\begin{array}{c}6 \\
12 \\
78.58 \pm 17.26 \\
79.81(69.15,95.65)\end{array}$ \\
\hline
\end{tabular}


Figure 1:

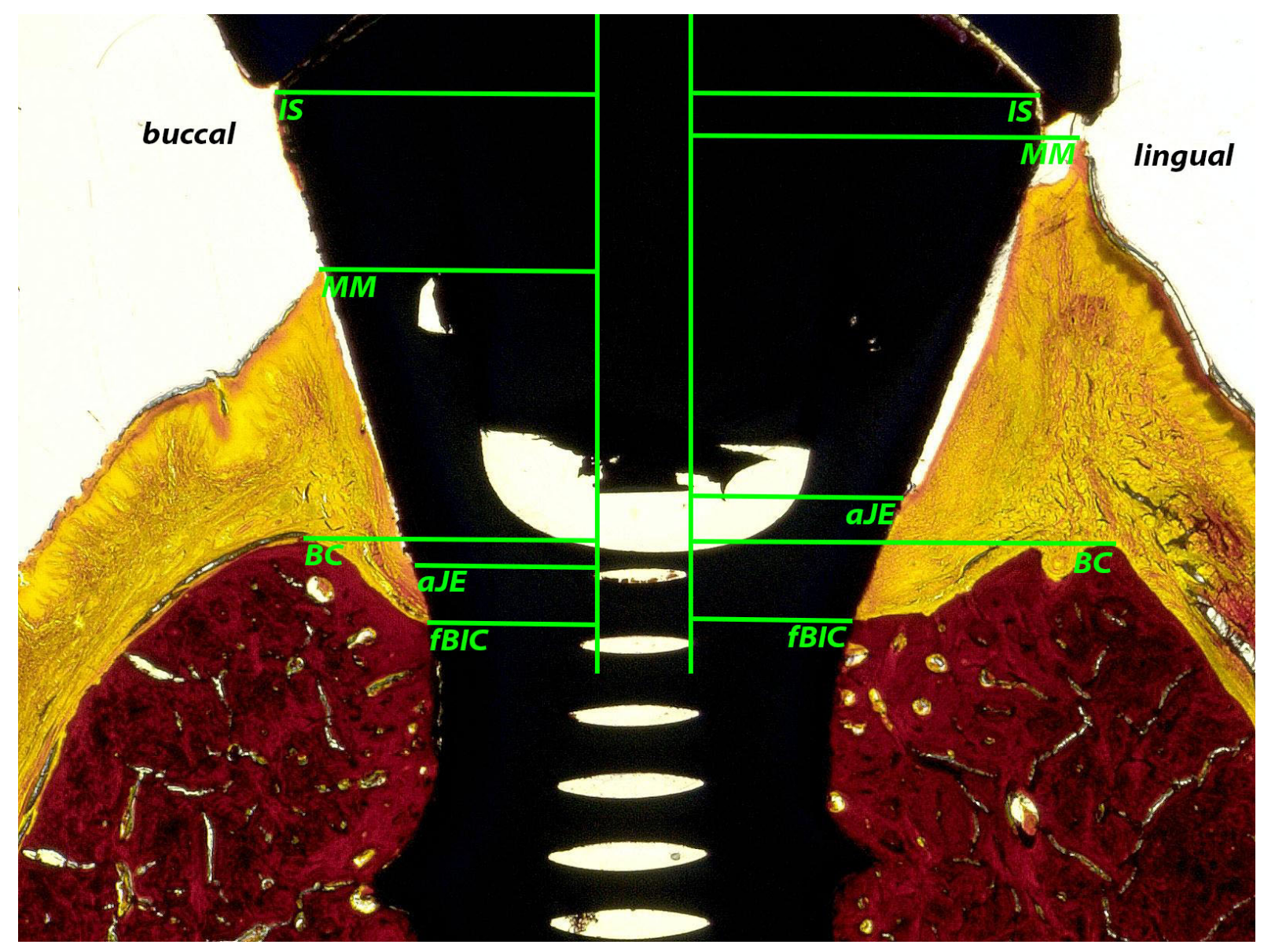


Figure 2:

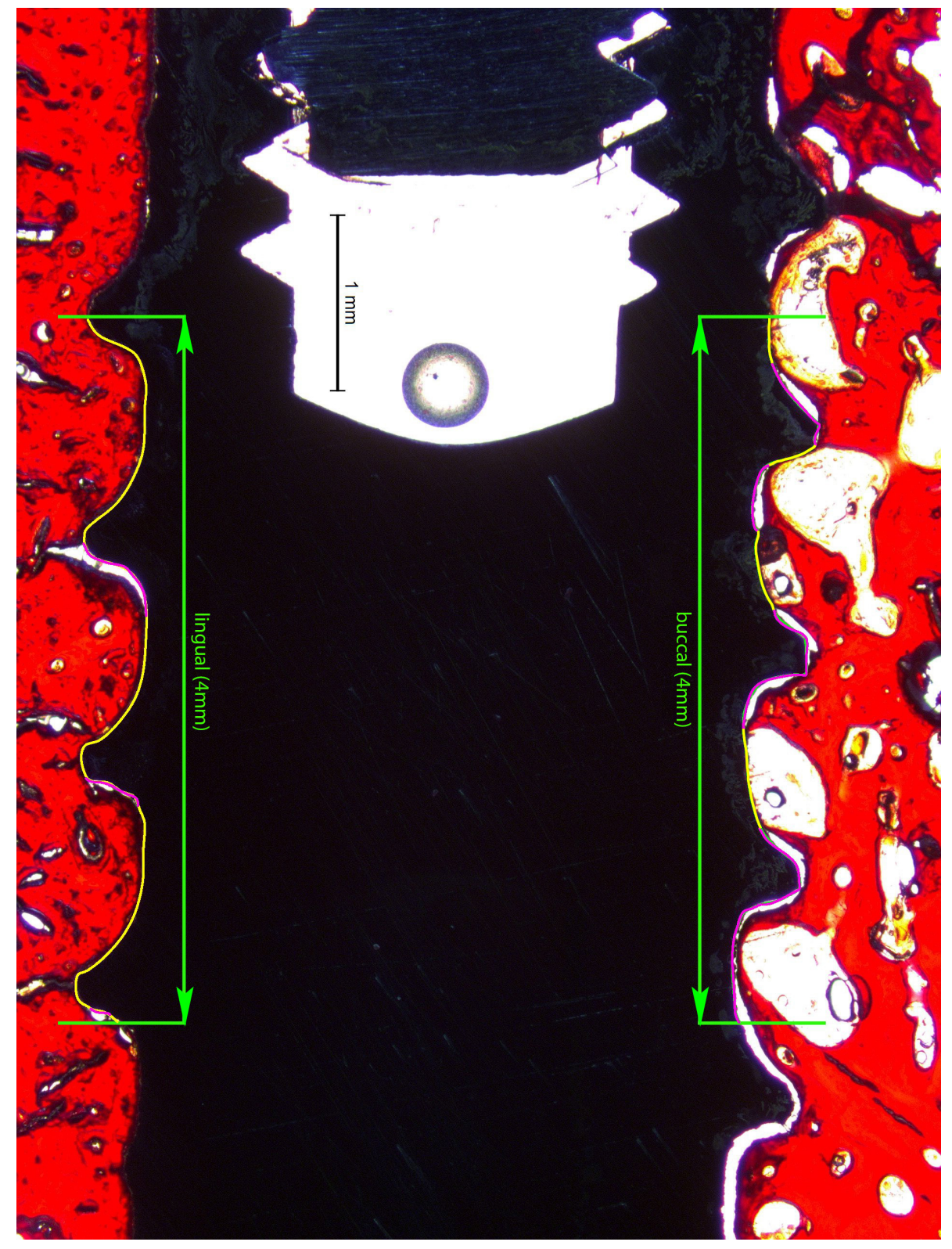


Figure 3a:

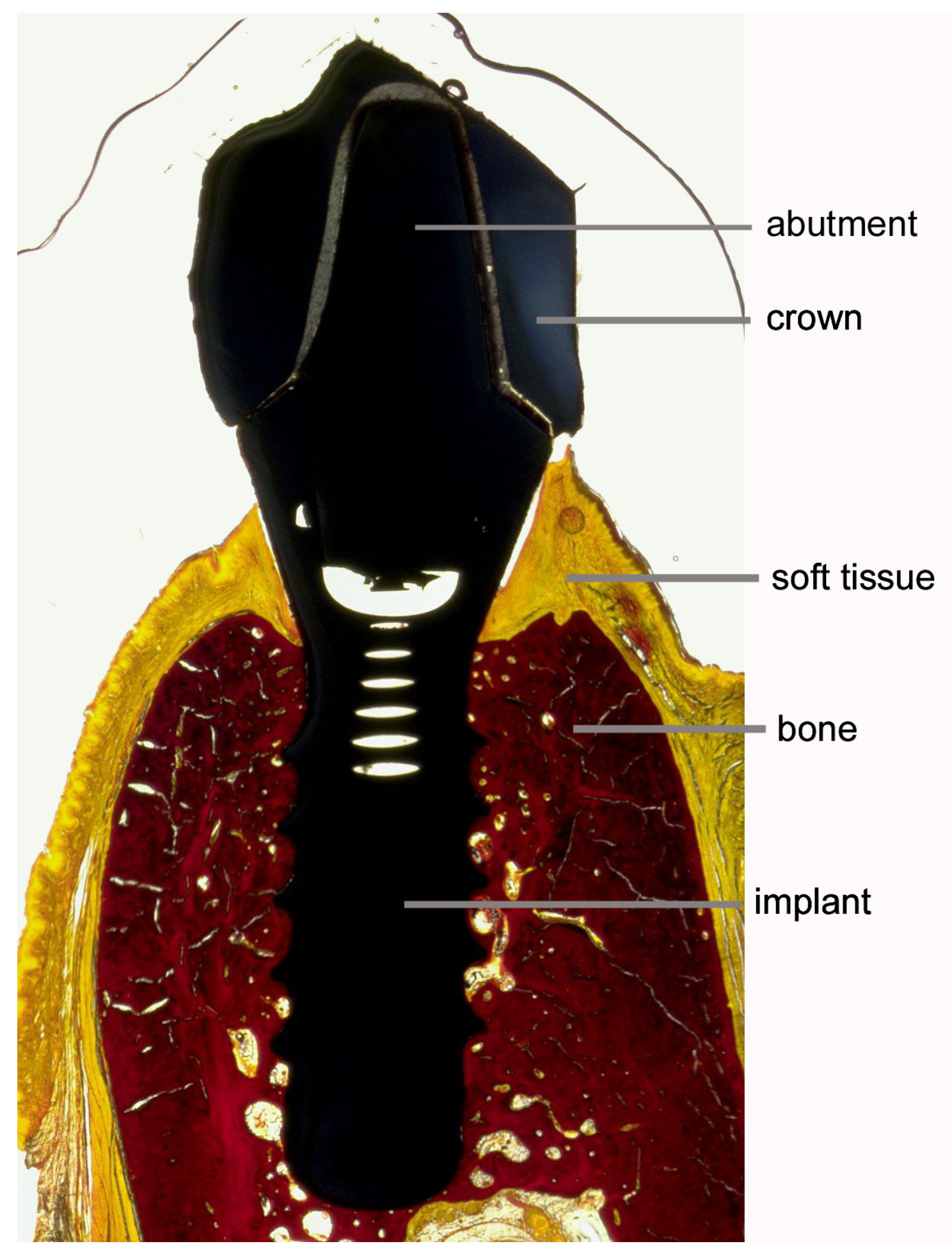


Figure 3b:

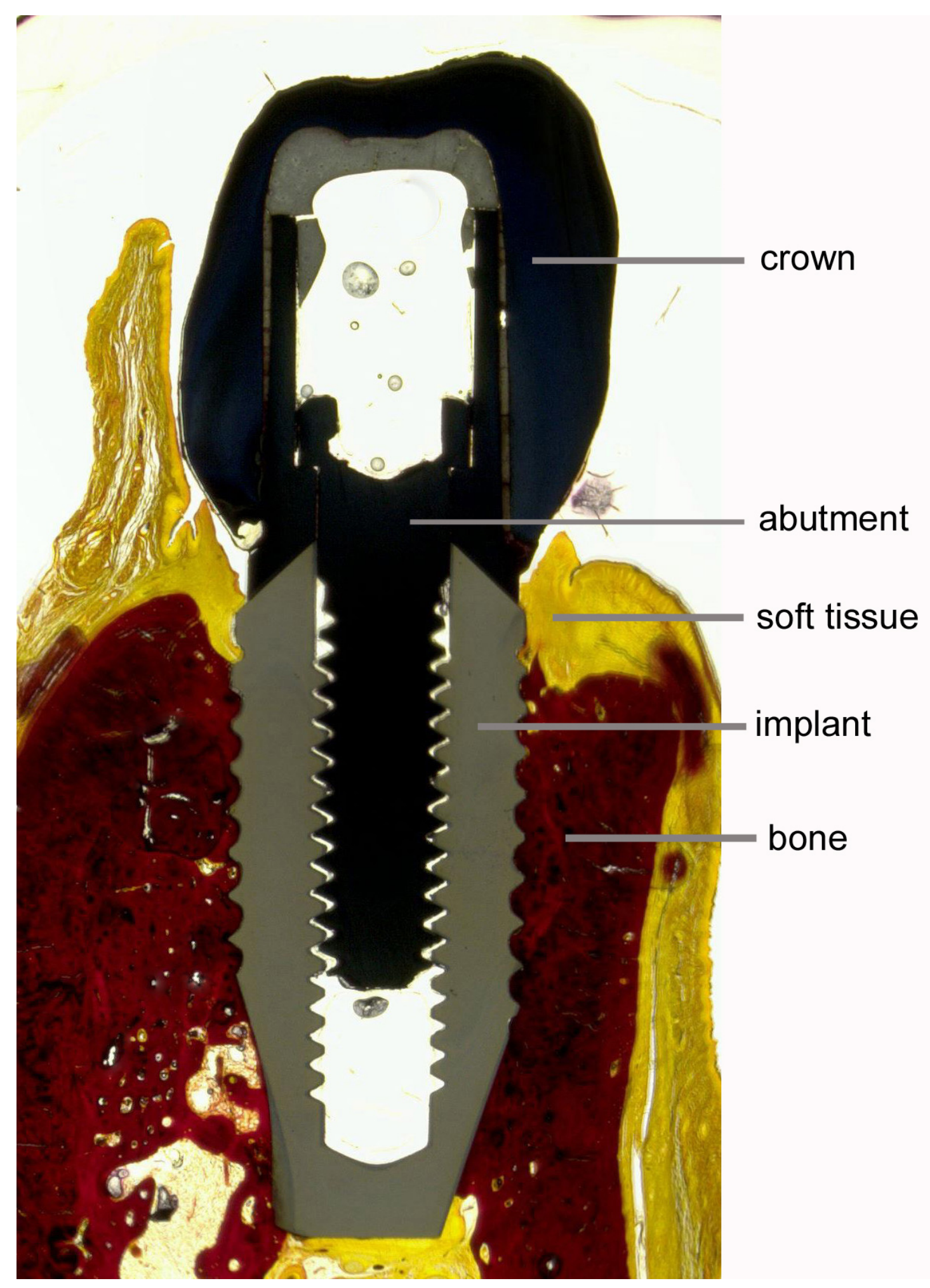


Figure 3c:

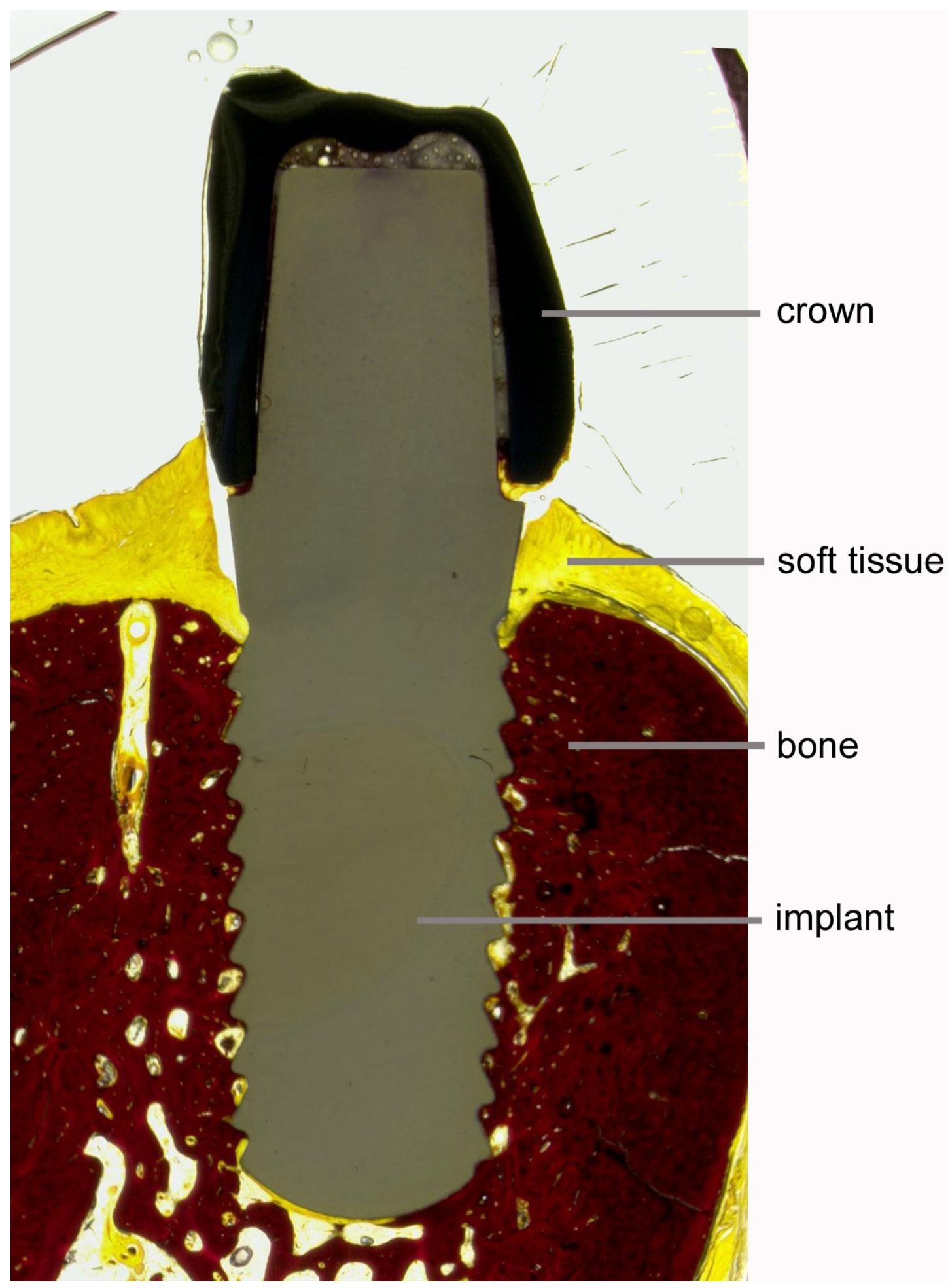


Figure 3d:

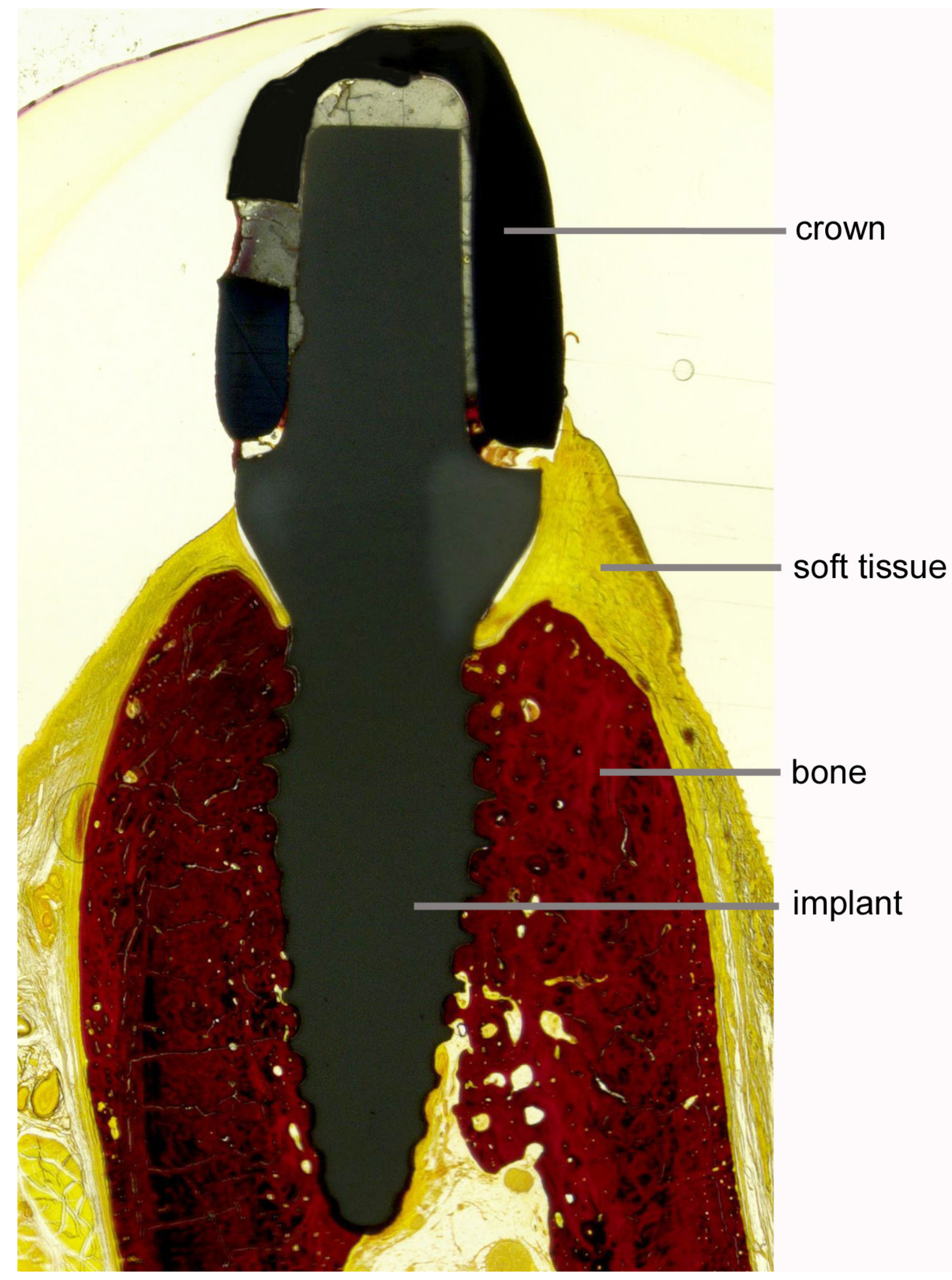

